\title{
高温高压下碱性橄榄玄武岩的 $\boldsymbol{P}$ 波速度及其 影响因素*
}

\author{
宋茂双谢酒森张月明侯渭 徐济安 ${ }^{(1)}$ 徐有生 \\ (中国科学院地球化学研究所地球深部物质实验室,贵阳 550002; \\ (1)台涾地球科学研究所, 台北)
}

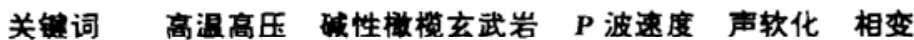

地震波反演是认识地球深部结构的有效手段之一, 尽管近年来高温高压波速就位测量的 实验技术得到了发展, 所能达到的压力七很高, 但仍然缺乏作为反演基础的地球深部物质在高 温高压条件下的波速及其影响因素的实验数据. 笔者选择蛇纹石化喊性橄榄玄武岩, 在 2.0 $\sim 5.0 \mathrm{GPa}$ 和温度达 $1500^{\circ} \mathrm{C}$ 范围内测量了 $P$ 波速度, 探讨了温度、压力、相变及其蛇纹石脱水 对 $P$ 波速度的影响, 发现在熔融前存在声软化效应, 并分析了声软化效应产生的机制.

\section{1 样品描述}

样品为采自内蒙古阿巴嘎旗的新生代碱性檄榄玄武岩, 其化学成分及其 CIPW 计算结果 列于表 1 中, 从表中可以看出 $\mathrm{TiO}_{2}$ 和结构水 $\mathrm{H}_{2} \mathrm{O}^{+}$的含量比较高. 构成该喊性檄榄玄武岩的 矿物包括单斜辉石 (透辉石)、斜长石 $\left(A n=58\right.$, 拉长石)、檄榄石 $\left(\mathrm{F}_{\mathrm{O}}=0.8\right.$, 贵檄榄石) 和铁钧氧 化物. 岩石具有斑状结构, 斑晶主要由檄榄石 组成, 沿着檄榄石颗粒内的裂隙及其附近发育 蛇纹石化, 以细纤维状集合体的形式存在, 少 量呈菱形片状, 是结构水的主要载体.

\section{$2 \boldsymbol{P}$ 波测量方法}

实验是在中国科学院地球化学研究所地 球深部物质实验室 YJ-3 000 吨压力机的六面 顶装置上进行的. 样品制成长 $33 \mathrm{~mm}$, 直径 $12 \mathrm{~mm}$ 的岩石柱. 传压介质为 $450^{\circ} \mathrm{C}$ 焙烧的 叶蜡石, 加热器选用 3 层不锈钢片. 高压腔体 的温度和压力标定在实验前进行, 温度标定采 用 PtRh10-Pt 热电偶进行, 而压力标定采用铜

表 1 实验样品的化学组成和 CIPW 计算结果

\begin{tabular}{|c|c|c|c|}
\hline \multicolumn{2}{|c|}{ 初始物的化学组成 } & \multicolumn{2}{|c|}{ CIPW 标准醇物计算结果 } \\
\hline 氧化物 & 含量 $/ \%$ & 标准矿物 & 含量/\% \\
\hline $\mathrm{SiO}_{2}$ & 46.25 & Or & 9.34 \\
\hline $\mathrm{TiO}_{2}$ & 4.34 & $\mathrm{Ab}$ & 24.64 \\
\hline $\mathrm{A}_{2} \mathrm{O}_{3}$ & 14.24 & An & 22.37 \\
\hline $\mathrm{FeO}$ & 9.73 & $\mathrm{Di}$ & 2.05 \\
\hline $\mathrm{Fe}_{2} \mathrm{O}_{3}$ & 4.33 & En & 12.99 \\
\hline $\mathrm{MgO}$ & 7.86 & Fs & 7.06 \\
\hline $\mathrm{CaO}$ & 5.64 & Fo & 5.00 \\
\hline $\mathrm{Na}_{2} \mathrm{O}$ & 2.82 & $\mathrm{Fa}$ & 3.00 \\
\hline $\mathrm{K}_{2} \mathrm{O}$ & 1.53 & Mt & 4.37 \\
\hline $\mathrm{P}_{2} \mathrm{O}_{5}$ & 0.24 & $\mathrm{Ilm}$ & 8.51 \\
\hline $\mathrm{H}_{2} \mathrm{O}^{-}$ & 2.59 & Ap & 0.54 \\
\hline 合计 & 99.57 & 合计 & 99.87 \\
\hline
\end{tabular}

1995-12-11 收稿, 1996-03-18 收修改稿

* 国家自然科学基金资助项目 
的熔点和柯石英相变方法. 波速测量采用超声波透射法, 即在某一温度压力下通过测量样品 的长度和超声波在样品中的走时求得其 $P$ 波速度, 本实验采用的测量方法和实验装置的详细 描述见文献[1].

\section{3 实验结果}

在 $2.0 \sim 5.0 \mathrm{GPa}$ 和温度达 $12500^{\circ} \mathrm{C}$ 范围内, 采用恒压升温的方式测量了䂸性檄榄玄武岩 的 $P$ 波速度. 图 1 是室温条件下实验前后 $P$ 波速度 $\left(V_{P}\right)$ 随压力变化的曲线, 图 2 为 2.0 , $3.0,3.5,4.0$ 和 $5.0 \mathrm{GPa}$ 压力下 $V_{P}$ 随温度 $(T)$ 变化的 $V_{P}-T$ 曲线, 表 2 给出了实验测得的一 些重要的 $V_{P}$ 数据. 测量结果表明, 室温下岩石的 $P$ 波速度 $\left(V_{P}^{0}\right)$ 随压力的升高而近似呈线性 增大(图 1). 另外随着温度的升高岩石的 $P$ 波速度表现出声软化效应, 即当温度大于声软化 温度 $T_{s}$ 时, $V_{P}$ 随温度的升高急剧降低 (图 2). 这种声软化效应可能类似于 Richet 等 ${ }^{2 j}$ 提出 的矿物嫆融前效应, 由于这种效应是通过 $V_{P} T$ 曲线反映出的, 所以称之为声软化效应. 压力 $\leqslant 3 \mathrm{GPa}$ 下, 温度小于 $T_{\mathrm{s}}$ 时 $V_{P}$ 随温度的升高而呈微弱的降低, 温度大于 $T_{\mathrm{s}}$ 时 $V_{P}$ 随温度的 升高而明显的降低. 压力 $\geqslant 3.5 \mathrm{GPa}$ 时, 发生声软化之前存在玄武岩-榴辉岩相变, 温度小于 相转变温度 $T_{\mathrm{e}}$ 时 $V_{P}$ 随温度的升高呈微弱的降低的趋势, 温度在 $T_{\mathrm{e}}$ 和 $T_{\mathrm{s}}$ 之间时随温度的 升高 $V_{P}$ 明显增大, 温度大于 $T_{\mathrm{s}}$ 时随温度的升高 $V_{P}$ 表现出明显降低的趋势. 在压力 $\leqslant 3$ $\mathrm{GPa}$ 时, 同样的压力下升温前的 $P$ 波速度 $\left(V_{P}^{0}\right)$ 和淬火后的 $P$ 波速度 $\left(V_{P}^{\prime}\right)$ 基本相同; 压力》 $3.5 \mathrm{GPa}$ 时, $V_{P}^{\prime}$ 较 $V_{P}^{0}$ 速度增大 $0.5 \mathrm{~km} / \mathrm{s}$ 左右, 并且 $\mathrm{d} V_{P}^{\prime} / \mathrm{d} p$ 也较 $\mathrm{d} V_{P}^{0} / \mathrm{d} p$ 要大(图 1).

对实验产物的分析鉴定表明, 压力小于 $3.5 \mathrm{GPa}$ 的产物没有形成石榴子石及其他矿物, 只 发生了蛇纹石脱水反应. 压力大于等于 $3.5 \mathrm{GPa}$ 的产物中存在石榴子石、富硬玉组分的辉石, $\mathrm{X}$ 射线衍射分析表明还存在石英. 蛇纹石脱水反应产物成分类似于顾火辉石. 温度的升高导 致石榴子石的镁铝榴石组分增加 ${ }^{[3,4]}$, 如在 $4.0 \mathrm{GPa}$ 压力的实验产物中石榴子石的镁铝榴石 组分含量在 $15 \% \sim 44 \%$, 而且, 压力的增大也会导致产物中石榴子石的镁铝榴石组分及辉石 中的硬玉组分增加 ${ }^{[4]}$.

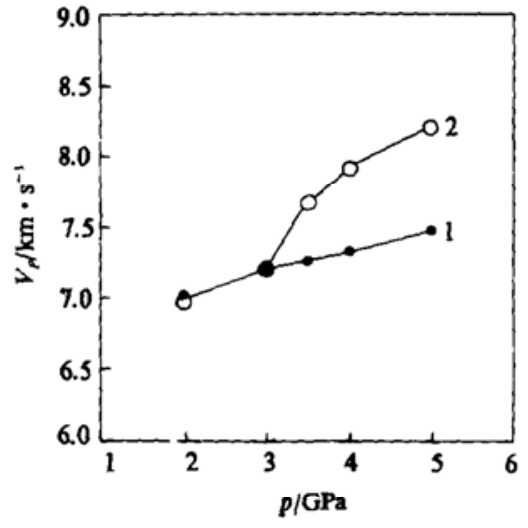

图 1 碱性檄模玄武岩的 $V_{P} p$ 曲线 1.2 分别为升温前、后的 $V_{P} p$ 曲线

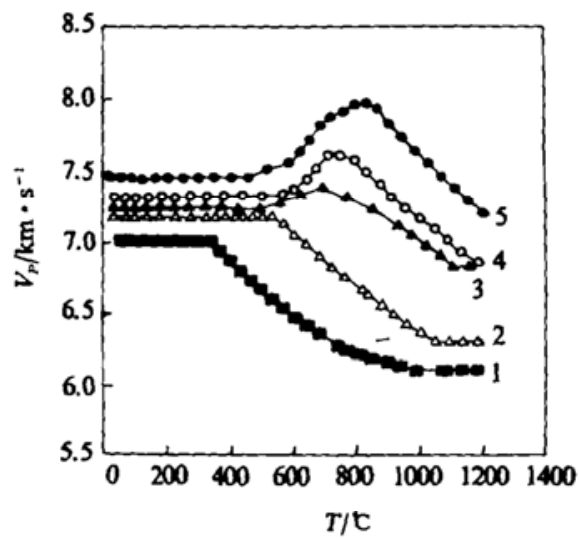

图 2 践性檄模玄武岩的 $V_{P} T$ 曲线 $1-2.0 \mathrm{GPa}, 2-3.0 \mathrm{GPa}, 3-3.5 \mathrm{GPa}$, $4-4.0 \mathrm{GPa}, 5-5.0 \mathrm{GPa}$ 
表 2 高温高压下㽣性做檻玄武岩的 $P$ 波测量的某些结果

\begin{tabular}{|c|c|c|c|c|c|c|c|c|}
\hline$p / \mathrm{GPa}$ & $v_{P}^{0} / \mathrm{km}^{-1} \mathrm{~s}^{-1}$ & $T_{\mathrm{e}} / \mathrm{C}$ & $\begin{array}{l}V_{P}\left(T_{e}\right) \\
/ \mathrm{km} \cdot \mathrm{s}^{-1}\end{array}$ & $T_{s} / \mathrm{C}$ & $\begin{array}{l}V_{P}\left(T_{\mathrm{s}}\right) / \\
\mathrm{km} \cdot \mathrm{s}^{-1}\end{array}$ & $T / \mathrm{C}$ & $\begin{array}{c}V_{P}(T) \\
/ \mathrm{km} \cdot \mathrm{s}^{-1}\end{array}$ & $\begin{array}{c}V_{\dot{p}} \\
/ \mathrm{kn}^{\prime} \cdot \mathrm{s}^{-1}\end{array}$ \\
\hline 2.0 & 7.023 & & & 348 & 7.018 & 1187 & 6.095 & 7.002 \\
\hline 3.0 & 7.213 & & & 511 & 7.202 & 1184 & 6.313 & 7.234 \\
\hline 3.5 & 7.275 & 501 & 7.267 & 704 & 7.422 & 1202 & 6.725 & 7.701 \\
\hline 4.0 & 7.332 & 553 & 7.328 & 762 & 7.575 & 1220 & 6.864 & 7.937 \\
\hline 5.0 & 7.474 & 528 & 7.468 & 835 & 7.969 & 1202 & 7.212 & 8.216 \\
\hline
\end{tabular}

\section{4 实验结果解释}

压力比较低时由于岩石产生破裂导致其波速值较低, 室温下 $2.0 \mathrm{GPa}$ 的 $P$ 波速度较其实 际值略低. $V_{P}$ 与压力的正相关关系及与温度的负线性关系已为许多实验所证实, 可能与物 质密度、压力和温度的相关关系有关，在 $2 \sim 5 \mathrm{GPa}$ 压力范围内蛇纹石脱水温度介于 $300 \sim$ $700 \mathrm{C}^{[5,6]}$, 与蛇纹石的类型有关, 利蛇纹石和纤蛇纹石的脱水温度较叶蛇纹石明显偏低 ${ }^{[6]}$. 根据显微镜下鉴定, 样品中的蛇纹石类型应为利蛇纹石和纤蛇纹石. 压力 $\leqslant 3 \mathrm{GPa}$ 时蛇纹石 脱水反应是导致岩石声软化效应产生的原因, 压力 $\geqslant 3.5 \mathrm{GPa}$ 时, 蛇纹石脱水温度明显低于相 应压力下的声软化温度, 而与相变温度比较接近. 蛇纹石脱水反应是糸武岩向榴辉岩相变的 重要原因, 从而使得温度介于 $T_{\mathrm{e}}$ 和 $T_{\mathrm{s}}$ 之间时 $V_{P}$ 与温度呈正的相关关系. 压力 $\geqslant 3.5 \mathrm{GPa}$ 时, 岩石的声软化效应可能与矿物中晶格缺陷及富汽液组分和玻璃物质的包裹体有关. 压力 $\geqslant 3.5 \mathrm{GPa}$ 时, 玄武岩-榴辉岩相变是造成 $V_{P}>V_{P}^{0}$ 的原因. 压力的增大会导致产物中石榴子 石及辉石的成分和矿物晶胞参数的变化, 温度的升高也导致石榴子石成分的改变, 这些因素是 $\mathrm{d} V_{P}^{\prime} / \mathrm{d} p$ 明显大于 $\mathrm{d} V_{P}^{0} / \mathrm{d} p$ 的主要原因.

\section{参考 文 献}

1 谢鸿森, 张月明、馀惠刷等。离温高压下测量岩石矿物波速的新方法及其意义，中国科学、B 辑, 1993，23(8):861一 864

2 Richet P. Ingrin J, Mysen B O et al. Premelting effects in minerals: an experimental study. Earth and Planetary Science Letters, 1994, 248:337 -345

3 Haselton H T, Newton R C. Thermodynamics of pyrope-grossular garnets and their stabilities at high temperatures and high pressures. Journal of Geophysical Research, 1980, 85(B12):6 973 6982

4 Poli S. The amphibolite-eclogite tranformation: an experimental study on basalt. American Journal of Science, 1993, 293 : $1061 \sim 1107$

5 Yui $\mathrm{T} \mathrm{F}$, Yeh $\mathrm{HW}$, Wang Lee $\mathrm{C}$. A stable isotope study of serpentinization in the Fengtien ophiolite, Taiwan. Geochimica et Cosmochimica Acta, 1990, 54:1 417 1 426

6 Tatsurmi Y. Migration of fluid phases and genesis of basalt magamas in subduction zones. Journal of Geophysicsl Research, 1989, $94: 4697 \sim 4707$ 